\title{
APROVEITAMENTO DO RESÍDUO DO CAFÉ NA ALIMENTAÇÃO DE TILÁPIA DO NILO
}

\author{
PROFITING COFFEE RESIDUE IN FEEDING OF NILE TILAPIA
}

\author{
Pimenta, C.J. ${ }^{1}$, Oliveira, M.M. ${ }^{2 *}$, Ferreira, L.O. ${ }^{1 \mathrm{~B}}$, Pimenta, M.E.S.G. ${ }^{1}$, Logato, P.V.R. $^{3}$, \\ Leal, R.S. ${ }^{1}$ e Murgas, L.D.S. ${ }^{2}$
}

\begin{abstract}
'Departamento de Ciência dos Alimentos. Universidade Federal de Lavras. Brasil. Bblarioliv@hotmail.com Departamento de Medicina Veterinária. Universidade Federal de Lavras. Brasil. *marinez.moraes@ig.com.br

32Departamento de Zootecnia. Universidade Federal de Lavras. Brasil. cpriscila@ufla.br
\end{abstract}

\section{PalaVRas CHAVE ADICIONAIS}

Ração. Digestibilidade. Desempenho. Composição quimica. Oreochromis niloticus.

\section{RESUMO}

O trabalho propôs avaliar formas de inclusão de resíduos de café na ração para alimentação de tilápia do Nilo. Foram realizados três ensaios: 1-composição química das rações; 2 -digestibilidade das rações e 3-desempenho de tilápias recebendo as rações contendo diferentes formas de inclusão dos resíduos de café. Foram testados os seguintes tratamentos: T1-ração referência; T2-ração com resíduo de café pré-seco em estufa; T3-ração com resíduo de café mantido em condições aeróbicas acrescido de soro de leite e melaço; T4ração com silagem ácida de resíduo de café com ácido fórmico; T5-ração com silagem de resíduo de café com soro de leite. Esses resíduos substituíram $30 \%$ da ração referência, sendo as rações posteriormente peletizadas. O tratamento T5 foi o que resultou em maior ganho de peso e consumo de ração. Os tratamentos T1 e T2 não diferiram entre si, apresentando valores próximos ao T5. Os tratamentos T6 e T7 apresentaram menor ganho de peso e consumo de ração e ainda maior conversão alimentar.

\section{SUMMARY}

This work evaluated different ways to include residues from coffee in Nile tilapia ration. Three assays were conducted: 1-rations chemical

\section{AdDitiOnAL KEYWORDS}

Ration. Digestibility. Performance. Chemical composition. Oreochromis niloticus.

composition; 2-digestibility and 3-tilapia performance fed with different ways to include residues of coffee on ration. The following treatments were tested: T1-basal ration; T2-stove pre-dried coffe residue ration; T3-ration with residue from coffee maintained under aerobic conditions added serum of milk and nolasses; T4-ration with acid ensilage of residue from coffee with formic acid; T7-ration with ensilage of residue from coffee with serum of milk. Those residues replaced $30 \%$ of the basal ration. The physical form of the ration was pelleted. The treatment $T 5$ resulted in greater weight gain and feed consumption and lesser feed conversion. The treatments T1 and T2 did not defer between itself presenting close values to the T5. The treatments T6 and T7 presented lesser weight gain and ration consumption and greater feed conversion.

\section{INTRODUÇÃO}

Atualmente o Brasil é o maior produtor mundial de grãos de café. Os principais resíduos da cultura são a polpa, a casca, a mucilagem e a água residual. A utilização de resíduos do café tem sido visto nos paises produtores como uma prioridade, tanto por razões ecológicas como por razões 
econômicas e sociais (Gomez-Brenes et al., 1988). Esforços são realizados para reciclá-los, através da elaboração de compostagens, produção de fertilizantes orgânicos, biogás e utilização na alimentação animal, como fonte de energia (Pulgarin et al., 1991).

Dentre os resíduos, o mais estudado em nível mundial é a polpa de café. Este é um subproduto obtido durante o processamento, com grande capacidade poluente. Em alguns países é utilizada como fertilizante (Donkoh et al., 1988). De acordo com alguns trabalhos, a polpa contém cerca de $6,5 \%$ de pectina, 23 a $27 \%$ de açúcares fermentáveis (peso seco), principalmente frutose (10 a $15 \%)$, sacarose $(2,8$ a $3,2 \%)$ e galactose (1,9 a 2,4\%) (Antier et al., 1993).

O primeiro passo para determinar o valor nutritivo de alimentos alternativos é a análise química, pois, através da mesma, determinase se existe condições de ser potencialmente utilizado. Análises prévias realizadas com o resíduo de café constataram teores médios de $10,52 \%$ para proteína bruta; $52,78 \%$ de fibra em detergente neutro e $39,76 \%$ de fibra em detergente ácido, na matéria préseca. Assim como outros resíduos, as altas quantidades de fibra e a presença de fatores antinutricionais podem causar problemas quando fornecidos aos animais, principalmente no que diz respeito a ganho de peso. As espécies animais aproveitam de forma diferente os alimentos, sendo essa variação quantificada através da determinação dos coeficientes de digestibilidade (Andrigueto et al., 1982). O conhecimento da digestibili- dade dos subprodutos da agro-indústria tem viabilizado a utilização de uma série de ingredientes em rações completas para peixes.

O desempenho dos animais, inclusive o do homem, depende da digestibilidade dos nutrientes e da extensão com que estes nutrientes podem ser absorvidos e utilizados. Os fatores antinutricionais podem interferir na digestibilidade, absorção e utilização dos nutrientes pelo organismo provocando efeitos negativos no crescimento ou na saúde dos animais. Dentre as substâncias que as plantas geralmente contêm e que exercem efeitos antinutricionais, podemse citar o ácido oxálico, o nitrato, os inibidores de tripsina e os polifenóis.

Diante deste contexto, a fim de proporcionar uma fonte de renda para os produtores e evitar problemas ambientais relacionados ao descarte da casca de café cereja, o objetivo do presente trabalho foi caracterizar quimicamente as rações obtidas com a inclusão de resíduo de café submetido a diferentes tratamentos, avaliar a digestibilidade dessas rações e determinar o desempenho de tilápias recebendo as rações experimentais com a inclusão $30 \%$ de resíduoem substituição ao milho.

\section{MATERIALE MÉTODOS}

O café foi processado conforme descrito por Pimenta (2003). A casca e a mucilagem retiradas do descascamento do café cereja constituíram o resíduo estudado. O resíduo de café foi associado ao soro de leite, melaço

Tabela I. Diferentes silagens de resíduo de café. (Different silages of coffee residue).

\begin{tabular}{ll}
\hline & Tratamento \\
\hline T1 & Ração referência \\
T2 & Resíduo de café pré-seco em estufa (in natura) \\
T3 & Silagem resíduo de café em condições aeróbicas $+10 \%$ de soro de leite $+10 \%$ de melaço \\
T4 & Silagem ácida de resíduo de café com ácido fórmico $3 \%$ \\
T5 & Silagem de resíduo de café $+10 \%$ de soro de leite (anaeróbia) \\
\hline
\end{tabular}

Archivos de zootecnia vol. 60, núm. 231, p. 584. 


\section{APROVEITAMENTO DO RESÍDUO DO CAFÉ NA ALIMENTAÇÃO DE TILÁPIA DO NILO}

e outras substâncias. Aplicou-se diferentes tratamentos para a obtenção das silagens com resíduos de café, conforme pode ser verificado na tabela $\mathbf{I}$.

Após a pré-secagem dos resíduos e silagens, estes foram incluídos em uma proporção de $30 \%$ na ração referência, formulada à base de milho e farelo de soja (tabela II), obtendo-se: T1-ração referência, a base de milho e farelo de soja; T2-ração com resíduo de café pré-seco em estufa in natura; T3-ração com resíduo de café mantido em condições aeróbicas acrescido de soro de leite e melaço; T4-ração com silagem ácida de resíduo de café com ácido fórmico; T5-ração com silagem de resíduo de café com soro de leite. A forma física da ração foi a peletizada.

\section{COMPOSIČÃO QUÍMICA}

As análises químicas foram realizadas no Laboratório de Produtos Vegetais do DCA/ UFLA, através das seguintes metodologias: umidade por gravimétria pela secagem em estufa a $105^{\circ} \mathrm{C}$ até peso constante (AOAC, 1990); proteína bruta, método microkjeldahl (AOAC, 1990); fibra em detergente neutro (FDN) e fibra em detergente ácido (FDA) segundo Van Soest y Wine, descrita por Silva (1990); cinza utilizou-se o método gravimétrico com aquecimento a $550^{\circ} \mathrm{C}$ (AOAC, 1990); extrato etéreo, aparelho tipo Sohxlet (AOAC, 1990) os compostos fenólicos totais foram extraídos pelo método de Goldstein y Swein (1963) utilizando como extrator o metanol $50 \%$ (U/V) e identificados de acordo com o método de Folin Denis, descrito pela AOAC (1990); o nitrato foi determinado segundo método proposto por Cataldo et al. (1975); ó ácido oxálico foi determinado segundo metodologia descrita pela AOAC (1990). Os inibidores de tripsina foram determinados segundo metodologia descrita em AACC (1976).

\section{DIGESTIBILIDADE}

O ensaio foi conduzido no Laboratório de Reprodução de Peixes da Estância da
Lagoa na cidade de Perdões, no período de julho a agosto de 2008 .

A determinaçoes do coeficiente de digestibilidade aparente (CDA) e energia metabolizável aparente foram realizadas pelo método indireto, sendo utilizado como indicador 1,0\% de óxido de cromo incorporado à ração, conforme metodologia descrita por Cho (1987) e Cho et al. (1985).

A dieta foi elaborada utilizando uma ração prática como referência sendo esta composta por $70 \%$ da ração referência (tabela II) $30 \%$ dos resíduos de café a ser testado segundo tabela de exigências para peixes (NRC, 1993).

Tabela II. Ração referência utilizada no ensaio de digestibilidade. (Reference diet used in the test of digestibility).

\begin{tabular}{lc}
\hline Ingredientes & Quantidade (kg) \\
\hline Milho & 61,00 \\
Farelo de soja & 30,00 \\
Fosfato bicálcico & 2,60 \\
Calcário calcítico & 1,60 \\
BHT & 0,20 \\
Aglutinante (alginato) & 0,20 \\
Sal comum & 0,50 \\
Caulim & 2,40 \\
Suplemento mineral e vitamínico ${ }^{1}$ & 0,50 \\
Óxido de crômio & 1,00 \\
Valores calculados: & \\
Proteína bruta (\%) & 30,00 \\
Energia digestível (kcal/kg) & 3000 \\
Cálcio total (\%) & 0,74 \\
Fósforo total (\%) & 0,60 \\
Fósforo disponível (\%) & 0,60 \\
Extrato etéreo (\%) & 4,60 \\
Fibra bruta (\%) & 3,76 \\
\hline
\end{tabular}

${ }^{1}$ Suplemento mineral e vitamínico (Supremais); Vit. $A=1200$ 000Ul; Vit. $D_{3}=200000 U I$; Vit. $E .=12000$ mg; Vit. $K_{3}=2400$ mg; Vit. $B_{1}=4800$ mg; Vit. $B_{6}=4000$ mg; Vit. $B_{12}=4800 \mathrm{mg}$; Ác. Fólico=1200 mg; Ác. Pantotênico $\mathrm{Ca}=12000 \mathrm{mg}$; Vit. $\mathrm{C}=48000 \mathrm{mg}$; Biotina $=48 \mathrm{mg}$; Colina $=65000 \mathrm{mg}$; Niacina $=24000$ $\mathrm{mg} ; \mathrm{Fe}=10000 \mathrm{mg} ; \mathrm{Cu}=6000 \mathrm{mg} ; \mathrm{Mn}=4000 \mathrm{mg}$; $\mathrm{Zn}=6000 \mathrm{mg} ; \mathrm{l}=20 \mathrm{mg} ; \mathrm{Co}=2 \mathrm{mg} ; \mathrm{Se}=20 \mathrm{mg}$. 
Foram utilizados 320 alevinos de tilápia do Nilo animais, distribuídos em 16 aquários inclinados com capacidade para 20 litros de água. Os alevinos de tilápia originaram-se do Laboratório de Reprodução da Estância da Lagoa, medindo em média $5 \mathrm{~cm}$ e com peso médio de $3 \mathrm{~g}$. Os tratamentos foram sorteados para o início da fase préexperimental, sendo 20 alevinos por aquário, onde, foram 7 tratamentos com as diferentes silagens e 1 tratamento com ração referência perfazendo um total de 8 tratamentos com 2 repetições, dois aquários receberam ração referência e os demais receberam $70 \%$ da ração referência $+30 \%$ dos resíduos de café.

Os alevinos receberam as dietas experimentais durante os três primeiros dias, denominado período préexperimental. O período experimental teve a duração de 7 dias com a coleta de fezes em todos eles.

A coleta de fezes foi feita 1 vez ao dia: às 7:30 horas, através de mangueira acoplada ao fundo do aquário e que o interliga ao coletor de fezes. A alimentação dos alevinos foi feita logo após a coleta de fezes, às 8:30 h, $12: 30$ h e às $16: 30$ horas. Após 30 minutos da última refeição, todos os aquários foram sinfonados com uma mangueira acoplada no fundo dos respectivos aquários, visando a eliminação dos restos da ração, fezes e resíduos; $70 \%$ da água era retirada para limpeza dos mesmos.

Toda a água era então drenada para a limpeza interna, ficando o sistema preparado para a coleta de fezes na manhã do dia seguinte.

As fezes livres caracterizaramse por pequenos grânulos, porém, quando decantadas no coletor de fezes, apresentaram-se amorfas.

Fezes e água foram acondicionadas em vidro, em seguida foram centrifugadas a $4200 \mathrm{rpm} / 8$ minutos a $20-22^{\circ} \mathrm{C}$, e secas em estufa a $65^{\circ} \mathrm{C}$. Aproximadamente 28 horas após a secagem estas foram maceradas e armazenadas em vidros com tampas, para posteriores análises.
Ao término do período de coleta, as amostras foram homogeneizadas e submetidas a análises bromatológicas segundo a AOAC (1990).

A temperatura média máxima durante o experimento foi $23^{\circ} \mathrm{C}$ e a temperatura média mínima foi de $17^{\circ} \mathrm{C}$.

Os coeficientes de digestibilidade aparente da matéria seca e dos nutrientes, além da energia digestível aparente foram determinados através da metodologia descrita por Cho (1987) e Cho et al. (1985).

As análises para determinação da concentração do cromo, nas fezes e ração teste, foram realizadas no Laboratório de Pesquisa Animal do Departamento de Zootecnia da Universidade Federal de Lavras, determinado por espectrofotometria de absorção atômica, descrita por Kimura y Miller (1957), para posteriores cálculos do coeficiente de digestibilidade (Mukhopadhyay y Ray, 1997; NRC, 1993).

\section{DESEMPENHO}

Após o experimento de digestibilidade, e escolha das silagens, realizou-se o ensaio de desempenho, substituindo $30 \%$ do milho, por resíduos de café.

Sendo escolhidas as silagens com melhor resposta à conservação, os tratamentos descartados, foram aqueles cujas características foram considerados impróprios para consumo, com alto grau de deterioração. $\mathrm{O}$ experimento foi realizado nas estruturas da Piscicultura da Estância da Lagoa, na cidade de Perdões, no período de Setembro/2008 a Janeiro/2009.

Foram utilizados 25 hapas confeccionados em tela mosquiteiro de $2 \mathrm{~m}$ de largura por 5 de comprimento, dispostos em viveiros de $400 \mathrm{~m}^{2}$. Foram utilizados 750 alevinos de tilápia nilótica (Oreochromis niloticus), medindo em média $5 \mathrm{~cm}$. Estes foram obtidos na Piscicultura Estância da Lagoa.

Após a triagem, os animais foram alojados nos respectivos hapas, que constituíram as unidades experimentais. Em cada hapa foram colocados 30 alevinos. Os hapas 


\section{APROVEITAMENTO DO RESÍDUO DO CAFÉ NA ALIMENTAÇÃO DE TILÁPIA DO NILO}

ficaram $80 \mathrm{~cm}$ debaixo da água e $20 \mathrm{~cm}$ acima, sempre na parte mais profunda do viveiro.

Foi utilizado o delineamento inteiramente casualizado, sendo 5 tratamentos e 5 repetições (hapas). A ração referência foi fornecida quatro vezes ao dia, às 9:00 horas, 11:30 horas, 14:00 horas e 16:00 horas, na proporção de $10 \%$ do peso vivo.

$\mathrm{O}$ período pré-experimental teve a duração de 5 dias, quando foram eliminados os animais não adaptados e ainda reposta a quantidade de peixes que morreram. Após o período pré-experimental, iniciou-se o período experimental com as rações com $30 \%$ de resíduo em substituição ao milho, com a duração de 120 dias. No primeiro dia, os alevinos foram pesados para a correção da quantidade de ração a ser fornecida a partir do início do experimento.

A partir de então, foi realizada biometria a cada 10 dias, tanto para fazer o ajuste da ração, como para avaliar o ganho de peso, altura e comprimento. Os peixes de cada hapa foram pesados em grupos de 10 unidades para maior precisão. Para obter a altura e o comprimento, 10 peixes de cada hapa foram medidos com uma régua graduada em milimetro.

As rações experimentais da tabela III foram formuladas com diferentes fontes de silagem de resíduo de café em substituição à $30 \%$ do milho na ração, de acordo com as exigências para a espécie, conforme NRC (1993), sendo elas isocalóricas e isoprotéicas.

O comprimento total foi considerado da cabeça à cauda e a altura do dorso ao ventre.

Para a biometria, os alevinos foram retirados das hapas com puçás. As avaliações foram feitas o mais rápido possível para evitar o estresse.

Para a elaboração das rações experimentais, os alimentos foram processados individualmente em um moinho com peneira de 0,5 mm. Após, foram misturados para garantir uma mistura homogênea.

Para o fornecimento aos alevinos, as rações foram desintegradas e peneiradas para adaptar-se ao tamanho da boca dos mesmos. $\mathrm{O}$ pH e nitrogênio amoniacal $(\mathrm{mg} / \mathrm{l})$ da água do viveiro foram medidos no início e final do experimento, sendo o pH médio igual 6,0 e o nitrogênio amoniacal médio de $0,115 \mathrm{mg} / \mathrm{l}$.

Os dados obtidos das diferentes fontes de silagens, ao final do experimento foram submetidos à análise estatística separadamente. Os dados obtidos ao final do experimento foram submetidos à análise estatística, utilizando o pacote computacional SAEG (1997).

\section{RESULTADOSEDISCUSSÃO}

A composição química média das rações experimentais encontra-se na tabela IV. De todas as variáveis analisadas, apenas extrato etéreo, ácido oxálico e inibidor de tripsina não diferiram estatisticamente $(p>0,05)$ ao se aplicar os diferentes tratamentos. Os valores médios de extrato etéreo observados foram inferiores aos normalmente utilizados em rações comerciais para peixe, $o$ que provavelmente influenciou o desempenho das tilápias utilizadas no presente trabalho. A ingestão de ácido oxálico, acima de 5\% na matéria seca, causa certa irritação gastrointestinal, contração muscular ou tetania, acompanhado por outros sintomas orgânicos (Luck, 1979). Em média o teor de ácido oxálico foi baixo, estando, portanto, dentro do padrão.

Os inibidores de tripsina não foram detectados nas amostras, o que constitui um ponto positivo para cada uma das formas de processamento.

A umidade na ração contendo resíduo de café préseco em estufa foi semelhante àquela observada na ração referência e situouse abaixo do valor máximo esperado em rações, que situase próximo a $10 \%$. As rações contendo as outras formas de processamento do resíduo de café apresentaram valores maiores para essa variável $(11,28$ a 14,20\%), sendo que a ração com adição de silagem ácida apresentouse mais úmida que as demais $(14,20 \%)$. Da 
PIMENTA, OLIVEIRA, FERREIRA, PIMENTA, LOGATO, LEALE MURGAS

Tabela III. Rações experimentais com diferentes fontes de resíduo de café em substituição ao milho. (Experimental diets with different sources of coffee residue in place of maize).

\begin{tabular}{|c|c|c|c|c|c|}
\hline Ingredientes\% & $\mathrm{T} 1$ & $\mathrm{~T} 2$ & T3 & T4 & T5 \\
\hline Farelo de soja & 57,50 & 57,60 & 57,58 & 57,58 & 57,58 \\
\hline Farinha de peixe & 24,00 & 24,00 & 24,00 & 24,00 & 24,00 \\
\hline Milho & 5,76 & 4,03 & 4,03 & 4,03 & 4,03 \\
\hline Resíduo de silagem de café & 0,00 & 1,72 & 1,72 & 1,72 & 1,72 \\
\hline Fosfato bicálcico & 0,09 & 0,09 & 0,09 & 0,09 & 0,09 \\
\hline Caulim & 3,35 & 3,26 & 3,28 & 3,28 & 3,28 \\
\hline Sal & 0,30 & 0,30 & 0,30 & 0,30 & 0,30 \\
\hline $\mathrm{BHT}$ & 0,10 & 0,10 & 0,10 & 0,10 & 0,10 \\
\hline Óleo de soja & 8,60 & 8,60 & 8,60 & 8,60 & 8,60 \\
\hline Supremais ${ }^{1}$ & 0,20 & 0,20 & 0,20 & 0,20 & 0,20 \\
\hline Vitamina C & 0,10 & 0,10 & 0,10 & 0,10 & 0,10 \\
\hline TOTAL & 100 & 100 & 100 & 100 & 100 \\
\hline \multicolumn{6}{|l|}{ Valores calculados } \\
\hline Proteína bruta & 42,0 & 42,0 & 42,0 & 42,0 & 42,0 \\
\hline E.M. (kcal/kg) & 2880 & 2880 & 2880 & 2880 & 2880 \\
\hline Cálcio & 0,135 & 0,143 & 0,147 & 0,147 & 0,156 \\
\hline Fósforo & 0,098 & 0,098 & 0,098 & 0,097 & 0,097 \\
\hline
\end{tabular}

'Suplemento mineral e vitamínico (Supremais): Vit. A: 1200 000Ul; Vit. D3: 200 000Ul; Vit. E: 12000 mg; Vit. K3: 2400 mg; Vit. B1: $4 ! 800$ mg; Vit. B6: 4000 mg; Vit. B12: 4800 mg; Ác. Fólico: 1200 mg; Ác. Pantotênico Ca: 12000 mg; Vit. C: 48000 mg; Biotina: 48 mg; Colina: 65000 mg; Niacina: 24000 mg; Fe: 10000 mg; Cu: 6000 mg; Mn: 4000 mg; Zn: 6000 mg; I: 20mg; Co: 2 mg; Se: 20 mg.

umidade depende a melhor ou pior conservação do material, pois está relacionada com estabilidade. Altos níveis de umidade propiciam a proliferação de fungos produtores de toxinas e, portanto, indicam que o armazenamento das rações contendo resíduo de café mantido em condições aeróbicas acrescido de soro e melaço, silagem ácida de resíduo de café com ácido fórmico, silagem de resíduo de café com soro de leite, pode constituirse um problema a ser resolvido em novos trabalhos. Apesar do valor mais alto de umidade ter sido observado na ração contendo silagem ácida, vale ressaltar que as demais formas de inclusão de resíduos são igualmente problemáticas uma vez que, além da alta umidade, possuem condições altamente satisfatórias para o desenvolvimento de microrganismos.

A proteína é de grande importância na alimentação de peixes, principalmente para peixes que utilizam a proteína como fonte de energia. O requerimento de proteína depende do hábito alimentar, tamanho do peixe, fonte de proteína, conteúdo de energia da dieta, temperatura da água, freqüência de alimentação, função fisiológica e espécie (Logato, 1999). A utilização do resíduo na ração não alterou de forma negativa o teor de proteína nas diferentes rações. Todas elas apresentaram valores semelhantes ou superiores ao valor encontrado na ração basal.

Um dos entraves da utilização de resíduo na alimentação animal são as altas quantidades de fibra e a presença de fatores antinutricionais, que podem causar problemas quando fornecidos aos animais, principalmente no que diz respeito a ganho de peso.

As rações contendo resíduo de café 


\section{APROVEITAMENTO DO RESÍDUO DO CAFÉ NA ALIMENTAÇÃO DE TILÁPIA DO NILO}

Tabela IV. Caracterização química das rações contendo resíduo do café cereja «in natura» e submetido a diferentes tratamentos, valores médios obtidos para matéria integral. (Chemical characterization of the diets containing residue of the coffee cherry in natura and subjected to different treatments, average values for field integral).

\begin{tabular}{|c|c|c|c|c|c|}
\hline Tratamento & $\mathrm{T} 1$ & T2 & T3 & T4 & T5 \\
\hline Umidade(\%) & $8,41 d( \pm 0,07)$ & $8,82 d( \pm 0,21)$ & $13,14 b( \pm 0,03)$ & $14,20 \mathrm{a}( \pm 0,17)$ & $11,28 c( \pm 0,16)$ \\
\hline Extrato etéreo(\%) & $2,40 \mathrm{a}( \pm 0,49)$ & $2,54 a( \pm 0,12)$ & $1,35 \mathrm{a}( \pm 0,30)$ & $2,36 a( \pm 0,37)$ & $1,52 \mathrm{a}( \pm 0,38)$ \\
\hline Proteína(\%) & $17,21 b( \pm 0,72)$ & $19,69 a( \pm 0,67)$ & $18,19 \mathrm{ab}( \pm 0,63)$ & $16,77 \mathrm{~b}( \pm 0,63)$ & $19,10 \mathrm{a}( \pm 0,94)$ \\
\hline FDA(\%) & $6,41 d( \pm 0,80)$ & $15,93 a( \pm 0,62)$ & $7,99 \mathrm{~cd}( \pm 0,17)$ & $6,98 \mathrm{~d}( \pm 0,79)$ & $9,82 b( \pm 1,01)$ \\
\hline $\mathrm{FDN}(\%)$ & $22,90 \mathrm{c}( \pm 1,02)$ & $49,99 a( \pm 5,53)$ & $30,29 b( \pm 1,33)$ & $29,57 b( \pm 1,65)$ & $33,60 b( \pm 1,08)$ \\
\hline Cinza(\%) & $5,48 b( \pm 0,65)$ & $3,96 c( \pm 0,15)$ & $8,12 \mathrm{a}( \pm 0,16)$ & $7,25 a( \pm 0,31)$ & $8,01 \mathrm{a}( \pm 0,28)$ \\
\hline ENN(\%) ${ }^{*}$ & $61,62 \mathrm{a}( \pm 2,70)$ & $53,77 b( \pm 0,56)$ & $54,67 \mathrm{~b}( \pm 2,04)$ & $55,29 b( \pm 0,74)$ & $54,85 \mathrm{~b}( \pm 0,85)$ \\
\hline Fenólicos(\%) & $0,169 c( \pm 0,01)$ & $0,623 a( \pm 0,03)$ & $0,183 c( \pm 0,00)$ & $0,259 b( \pm 0,01)$ & $0,124 d( \pm 0,01)$ \\
\hline Nitrato(\%) & $0,104 c( \pm 0,01)$ & $0,135 \mathrm{a}( \pm 0,01)$ & $0,045 d( \pm 0,00)$ & $0,121 b( \pm 0,01)$ & $0,035 d( \pm 0,00)$ \\
\hline Acido oxálico(\%) & $0,207^{\mathfrak{a}}( \pm 0,01)$ & $0,237 a( \pm 0,01)$ & $0,434 a( \pm 0,15)$ & $0,434 \mathrm{a}( \pm 0,09)$ & $0,399 a( \pm 0,22)$ \\
\hline
\end{tabular}

Médias seguidas pela mesma letra minúscula na linha, não diferem entre si, a 5\% de probabilidade, pelo teste de Tukey.

*Extrato não nitrogenado (ENN).

mantido em condições aeróbicas acrescido de soro e melaço e silagem ácida de resíduo de café com ácido fórmico foram estatisticamente semelhantes à ração referência. Nesta última, o baixo teor de fibra em detergente ácido em relação às demais rações experimentais pode ser explicado pela presença do ácido fórmico que ajudou na degradação das fibras. Por sua vez, na ração contendo resíduo de café mantido em condições aeróbicas e acrescido de soro e melaço a fermentação, juntamente com a presença de moscas da fruta podem ter ajudado na degradação desse composto. A ração contendo resíduo de café pré-seco em estufa apresentou o maior teor de fibra dentre as rações com a inclusão de resíduo, o que pode ser explicado pela ausência de fermentação como os demais, pois segundo Barcelos (2001) o aumento do tempo de armazenamento da casca de café pode melhorar a taxa de degradação dos tecidos vegetais por microrganismos saprófitas aeróbios, disponibilizando açúcares prontamente solúveis. Será discutido mais adiante se este teor de fibra interferiu na digestibili- dade da ração e no desempenho dos peixes.

Quanto aos fenólicos, a ração contendo resíduo de café préseco em estufa apresentou valor bastante superior àquele observado nas demais ( $\mathrm{p}<0,05)$. Conceição (1998) relata, entretanto, na discussão de seu trabalho, que teores de fenólicos superiores a $1 \%$ em cultivares de sorgo, são considerados altos e prejudiciais à digestibilidade de proteínas. Os resultados encontrados para as rações estudadas situaramse entre $0,1 \%$ e $0,6 \%$ e, portanto, não oferecem risco.

Uma elevada ingestão de nitratos, que sob certas condições podem ser reduzidos a nitritos, representa um risco, por serem o ponto de partida para uma cadeia de reações que os converte em substâncias tóxicas. As rações analisadas não apresentaram um teor elevado de nitrato, sendo que aquela contendo resíduo de café préseco em estufa apresentou os maiores níveis $(\mathrm{p}<0,05)$.

Os coeficientes de digestibilidade aparente encontrados para as rações contendo as diferentes formas de inclusão de resíduo de café estão dispostos na tabela $\mathbf{V}$.

A exigência energética dos peixes é 
menor que a de outros animais, uma vez que os mesmos não necessitam de manter a temperatura corporal. Nas rações comerciais a fonte de energia é obtida basicamente dos carboidratos e dos lipídeos (Logato, 1999) e, portanto, o milho é considerado um ingrediente básico nas rações comerciais para peixes, elaboradas no Brasil.

A inclusão dos resíduos de café não afetou de forma significativa a digestibilidade do extrato etéreo, da proteína bruta e da fibra bruta, pois os tratamentos não apresentaram diferenças significativas em relação à ração referência $(\mathrm{p}>0,05)$. Tal fato mostra a possibilidade de se utilizar até $30 \%$ do resíduo em substituição ao milho, sem necessidade de tratamentos adicionais, no que se refere a digestibilidade. As rações analisadas apresentaram coeficientes de digestibilidade aparente superiores aos obtidos por Pezzato et al. (2002) para alimentos energéticos comumente utilizados em rações, com essa mesma espécie.

Se comparados com outros ingredientes alternativos podese perceber o alto valor dos coeficientes de digestibilidade aparente encontrados para as rações formuladas com o resíduo de café. Santos et al. (2007) determinaram a digestibilidade de rações com a inclusão de $30 \%$ de farelo de resíduo de goiaba e do farelo de coco. Os valores de digestibilidade do farelo de resíduo de goiaba foram de $43,36 \%$ para matéria seca e $61,49 \%$ para a proteína bruta e para o farelo de coco de $60,36 \%$ para matéria seca e $75,62 \%$ para proteína bruta. Furuya et al. (2001) trabalharam também com tilápia do Nilo e obtiveram um valor de digestibilidade aparente da proteína bruta de $86,92 \%$ para o farelo de canola (Brassica napus).

Com relação aos coeficientes de digestibilidade determinados, podese verificar que a tilápia do Nilo apresenta uma alta capacidade de aproveitamento do resíduo de café se compararmos com outros ingredientes citados.

Os valores encontrados para o ganho de peso, consumo de ração e conversão ali- mentar estão apresentados na tabela VI.

A ração contendo resíduo mantido em condições aeróbicas acrescido de soro e melaço foi a que resultou em maior ganho de peso e consumo de ração e melhor conversão alimentar $(p<0,01)$. Este fato corrobora os resultados em termos de composição química, pois este ingrediente alternativo, ao ser analisado quimicamente apresentou elevado teor de proteína e baixos teores de fibra, sendo portanto a melhor forma de preparo dos resíduos dentre os métodos analisados. A ração contendo resíduo de café pré-seco em estufa não diferiu estatisticamente da ração referência, apresentando valores próximos aos observados para a ração contendo resíduo mantido em condições aeróbicas acrescido de soro e melaço.

Vale ressaltar que as tilápias que receberam as rações contendo resíduo de café préseco em estufa e resíduo mantido em condições anaeróbicas acrescido de soro e melaço, assim como as que receberam a ração basal atingiram peso satisfatório para o abate ao final do período experimental de 6 meses. Os menores ganhos de peso e consumo de ração e maior conversão alimentar foram observados ao se utilizar as rações contendo silagem ácida e silagem com soro, sendo estas consideradas as piores opções entre os demais estudados.

Devido à ausência de trabalhos sobre a inclusão de resíduo de café na ração, os resultados serão comparados aos trabalhos com inclusão de outros alimentos alternativos.

No presente trabalho a inclusão de $30 \%$ de resíduo de café mantido em condições anaeróbicas acrescido de soro e melaço em substituição ao milho na ração proporcionou um maior ganho de peso que as demais rações analisadas.

Pezzato et al. (2000) trabalhando também com tilápias do Nilo demonstraram que a inclusão de até $30 \%$ de farelo de coco nas dietas proporcionou melhores resultados de ganho de peso.

Segundo Souza e Hayashi (2004) a 


\section{APROVEITAMENTO DO RESÍDUO DO CAFÉ NA ALIMENTAÇÃO DE TILÁPIA DO NILO}

Tabela $\boldsymbol{V}$. Coeficiente de digestibilidade aparente dos produtos obtidos através da inclusão de resíduos gerados no descascamento do café cereja elaborados de diferentes formas. (Coefficient of digestibility of the products obtained through the inclusion of waste generated in the stripping of the coffee cherry produced in different ways).

\begin{tabular}{lccccc}
\hline $\begin{array}{l}\text { Rações } \\
\text { Variáveis }\end{array}$ & T1 & T2 & T3 & T4 & T5 \\
\hline CDMS $(\%)^{*}$ & $99,99( \pm 1,35)$ & $99,91( \pm 1,50)$ & $99,99( \pm 0,01)$ & $99,95( \pm 0,21)$ & $99,94( \pm 0,01)$ \\
CDAEE $(\%)^{*}$ & $99,96( \pm 0,54)$ & $99,95( \pm 0,23)$ & $99,81( \pm 0,01)$ & $99,97( \pm 0,01)$ & $99,94( \pm 0,04)$ \\
CDAPB $(\%)^{*}$ & $99,93( \pm 0,01)$ & $99,95( \pm 0,02)$ & $99,81( \pm 0,06)$ & $99,97( \pm 0,05)$ & $99,95( \pm 0,06)$ \\
CDAFB $(\%)^{*}$ & $99,99( \pm 0,01)$ & $99,75( \pm 0,64)$ & $99,77( \pm 0,01)$ & $99,81( \pm 1,22)$ & $99,73( \pm 0,09)$ \\
\hline
\end{tabular}

*Não houve diferença significativa entre as médias na mesma linha pelo Teste de Tukey a 5\% de probabilidade.

inclusão de até $20 \%$ de farelo de algodão à ração não altera de forma significativa o desempenho de tilápias do Nilo, um aumento nesse nível pode influenciar de maneira negativa no desempenho.

Guimarães et al. (2004) trabalhando com farinha de mandioca (Manihot esculenta) como ingrediente energético em rações para tilápia do Nilo, substituindo o milho nos níveis de $0,50,75$ e $100 \%$, concluíram que a farinha de mandioca pode substituir o milho em até $50 \%$ sem afetar o ganho de peso, a conversão alimentar e o rendimento de filé.

Como pode ser observado, o desempenho de tilápias do Nilo depende dos ingredien- tes utilizados, portanto, o estudo de diferentes ingredientes alternativos, bem como a concentração utilizada deste, torna-se muito importante quando se pretender avaliar a inclusão de um novo ingrediente em rações.

\section{CONCLUSÕES}

Nas condições do presente trabalho e correlacionando todas as variáveis estudadas, conclui-se que, dentre as formas de inclusão do resíduo de café, é viável substituir $30 \%$ de milho na ração pelo resíduo de café mantido em condições aeróbicas acrescido de soro de leite e melaço, uma

Tabela VI. Valores médios referentes ao ganho de peso, consumo de rações e conversão alimentar de tilápias recebendo resíduos de café cereja descascado preparado de diferentes formas. (Average values for the weight gain, consumption of diets and feed conversion of tilapia receiving waste peeled cherry coffee prepared in different ways).

\begin{tabular}{lccr}
\hline Rações & Ganho de peso(g) & Consumo de ração(g) & Conversão alimentar(g) \\
\hline T1 & $516,50 \mathrm{~b}( \pm 7,50)$ & $830,75 \mathrm{~b}( \pm 12,43)$ & $1,61 \mathrm{~b}( \pm 0,01)$ \\
T2 & $516,60 \mathrm{~b}( \pm 5,80)$ & $830,72 \mathrm{~b}( \pm 9,35)$ & $1,61 \mathrm{~b}( \pm 0,01)$ \\
T3 & $543,52 \mathrm{a}( \pm 7,38)$ & $834,40 \mathrm{a}( \pm 10,51)$ & $1,54 \mathrm{c}( \pm 0,01)$ \\
T4 & $394,50 \mathrm{c}( \pm 6,32)$ & $692,87 \mathrm{~d}( \pm 9,38)$ & $1,76 \mathrm{a}( \pm 0,02)$ \\
T5 & $395,22 \mathrm{c}( \pm 5,84)$ & $694,37 \mathrm{c}( \pm 11,89)$ & $1,76 \mathrm{a}( \pm 0,01)$ \\
\hline
\end{tabular}

Médias seguidas pela mesma letra minúscula na coluna, não diferem entre si, a 1\% de probabilidade, pelo teste de Tukey. 


\section{PIMENTA, OLIVEIRA, FERREIRA, PIMENTA, LOGATO, LEALE MURGAS}

vez que proporciona proteína bruta semelhante àquela apresentada pela ração referência, baixos níveis de fibra em detergente ácido e fibra em detergente neutro,

\section{BIBLIOGRAFIA}

AACC. 1976. Approved methods of the American Association of Cereal Chemists. $7^{\underline{a}}$ ed. Saint Paul. 256 pp.

Andrigueto, J.M., Perly, L., Minardl, I., Gemael, A., Fleming, J.S., Souza, G.A. e Bona-Filho, A. 1982. Nutrição animal. Nobel. Paraná. 395 pp.

Antier, P., Minjares, A., Roussos, S., Raimbault, M. and Viniegra-Gonzalez, G. 1993. Pectinasehyperproducing mutants of Aspergillus niger C28B25 for solid-state fermentation of coffee pulp. Enzyme Microb. Tech., 15: 254-260.

AOAC. 1990. Official methods of analysis. Association of Official Analytical chemists. 15 ed. Washington. $1018 \mathrm{pp}$.

Barcelos, A.F., Paiva, P.C.A., Peréz, J.R.O., Teixeira, J.C. e Cardoso, R.M. 2001. Avaliação da casca e da polpa desidratada de café (Coffea arábica L.) pela técnica de degradabilidade in vitro de produção de gás. Rev. Bras. Zootecn. 30: 1829-1836.

Cataldo, D.A., Haroon, M., Schrader, L.E. and Youngs, V.L. 1975. Rapid colorimetric determination of nitrate in plant tissue by nitration of salicytic acid. Soil Plant Anal., 6: 71 . 80

Cho, C.Y. 1987. La energía en la nutrición de los peces. In: Nutrición en Acuicultura II. Monteros, J.E. de los, Lanarta. U. Comisión Asesora de Investigaçión Científica y Técnica. Ed. Madrid. pp. 97-243.

Cho, C.Y., Cowey, C.B. and Watanabe, T. 1985. Finfish nutrition in Asia: methodological approaches to research and development. IDRC. Otawa. 154 pp.

Conceição, A. 1998. Caracterização de constituintes nutricionais e antinutricionais do resíduo industrial de laranja (Citrus sinensis $L$. Osbeck) cv. Hamlim submetido a diferentes tipos de secagens. Dissertação Mestrado em Ciências dos Alimentos. Universidade Federal de Lavras. $145 \mathrm{pp}$.

Donkoh, A., Atuahene, C.C., Kese, A.G. and Mensah Asante, B. 1988. The nutritional value of dried alto coeficiente de digestibilidade e um melhor desempenho para as tilápias. Deve-se, entretanto, atentar para a umidade, a qual aumenta bastante com esta prática.

coffee pulp (DCP) in broiler chickens diets. Anim. Feed. Sci. Tech., 22: 139-146.

Furuya, W.M., Pezzato, L.E., Miranda, E.C., Furuya, V.R.B., Barros, M.M. e Lanna, E.A.T. 2001. Digestibilidade aparente da energia e nutrientes do farelo de canola pela tilápia do Nilo Oreochromis niloticus. Rev. Bras. Zootecn., 30: 611-616.

Gomes-Brenes, R., Bendaña, G., Gonzáles, J.M. Jarquín, R., Braham, J.E. y Bressani, R. 1988. Efectos del tratamiento de la pulpa del café, fresca o ensilada com hidróxido de calcio, sobre su valor nutritivo. Arch. Latinoam. Nutr., 38: 173-187.

Guimarães, I.C., Miranda, E.C. e Fraga, A.B. 2004. Farinha de mandioca esculenta como ingrediente energético em rações para tilápia do nilo Oreochromis niloticus. Congresso Internacional de Zootecnia. Brasília.

Kimura, F.T. and Miller, V.L. 1957. Improved determination of chromic oxid in calf feed and feces. J. Agri. Food Chem., 5: 216.

Logato, P.V.R. 1999. Nutrição e alimentação de peixes de agua doce. UFLA/FAEPE. Lavras.

Luck, P.E. 1979. Setaria a important pasture grass. Queensland Agri. J., 2: 136-144.

Mukhopadhyay, N. and Ray, A.K. 1997. The apparent total and nutrient digestibility of sal seed (Shorea rubusta) meal in rohu, Labeo rohita (Hamilton), fingerlings. Aquac. Res., 28: 683-689.

NRC. 1993. Nutrient requirements of warm water, fishes and shellfishes: nutrient requirements of domestic animals. National Research Council. Washington. D.C. 114 pp.

Pezzato, L.E., Miranda, E.C. de, Barros, M.M., Pinto, G.Q., Pezzato, A.C. e Furuya, W.M. 2000. Valor nutritivo do farelo de coco para tilápia-donilo (Oreochromis niloticus). Acta Sci., 22: 695-699.

Pezzato, L.E., Miranda, E.C., Barros, M.M., Pinto, L.G.Q., Furuya, W.M., Pezzato, A.C. 2002. Digestibilidade aparente de Ingredientes pela 


\section{APROVEITAMENTO DO RESÍDUO DO CAFÉ NA ALIMENTAÇÃO DE TILÁPIA DO NILO}

tilápia do Nilo (Oreochromis niloticus). Rev. Bras. Zootecn., 31: 1595-1604.

Pimenta, C.J. 2003. Qualidade de café. Editora UFLA. Lavras. 304 pp.

Pulgarin, C., Schwitzguebel, J. e Tabacchi, R. 1991. Comment blanchir les residus du café noir. Biofutur, 102: 43-50.

SAEG. 1997. Sistema para análises estatísticas e genética. Versão. Universidade Federal de Viçosa. UFV. $150 \mathrm{pp}$.

Santos, E. L., Ludke, C.M.M. M. do, Barbosa, J.M., Rabello, C.BV., Ludke, J.V., Ramos, A. M. de P.,
Lima, M.R. de e Pessoa, W.V.N. 2007. Digestibilidade do farelo de coco e resíduo de goiaba pela tilápia-do-Nilo (Oreochromis niloticus). Dissertação. Universidade Federal de Lavras. 70 pp.

Silva, D.J. 1990. Análise de alimentos (métodos químicos e biológicos). Universidade Federal de Viçosa. 166 pp.

Souza, S.R. de, Hayashi, C. 2004. Desempenho de alevinos de tilápia do Nilo submetidos a diferentes níveis de inclusão do farelo de algodão. Ciênc. Agrárias, 25: 151-158. 